\title{
A Study of Resin as Master Jewellery Material, Surface Quality and Machining Time Improvement by Implementing Appropriate Cutting Strategy
}

\author{
Paryana Puspaputra \\ Department of Mechanical EngineeringIndonesia Islamic University. Jl. Kaliurang Km 14, Jogjakarta 55581 Indonesia
}

\begin{abstract}
This paper deals with a research about art and jewellery product machining that focused in the selection of appropriate material for jewellery master which is machined by CNC. CNC is used for better surface finish for no undercut design and more complex ornament. The need of production speed requires minimum process without reducing the quality of detail ornament significantly. Problems occur when high surface quality is required. In that condition high speed spindle is used with low feeding speed, as a result is high temperature in cutter-material area will melt the resin and build the build-up edge (BUE). Due to the existence of BUE, the cutting tool will no longer cut the resin, as a result the resin will then melt due to friction and the melt resin will then stuck on the relief and surface finish become worst and rework should be done. When required surface is achieved problem also occur in next going process, that is silicon mould making. Due to galvanization process for silicon at about $170^{\circ} \mathrm{C}$, resin material may be broken or cracked. Research is then conducted to select appropriate resin type suitable for all production steps. Keywords: master product, $\mathrm{CNC}$, resin, micro-machining, jewellery, machining strategy.
\end{abstract}

\section{Introduction}

In a jewellery production which use investment casting process that is shown in Figure.1, a master is a most important part. The master product should have high quality either on surface or geometry. Traditionally a master is made by a high skilled craft man, but recently it is made by using a $\mathrm{CNC}$ or rapid prototyping machine.

In a product which have small sized as it is shown in Figure.2, complex and detail relief, high quality surface finished is very difficult to achieved due to material properties, brittleness and melting point and grain size is sometimes become obstacles.

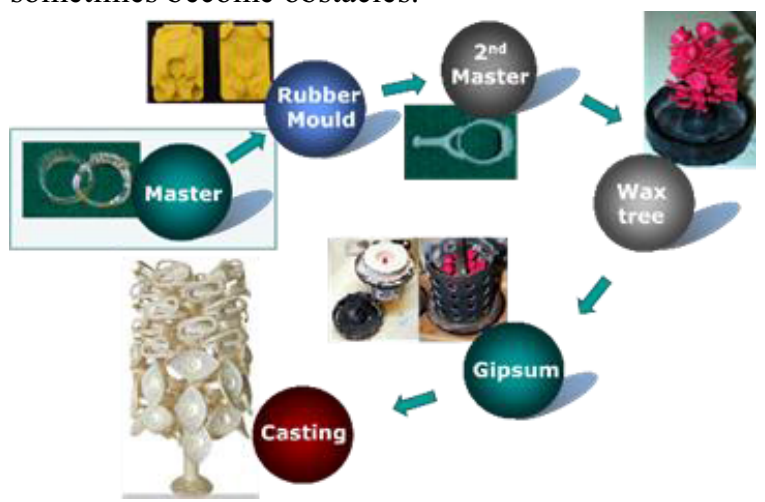

Figure 1. Jewellery production process using investment casting [1]

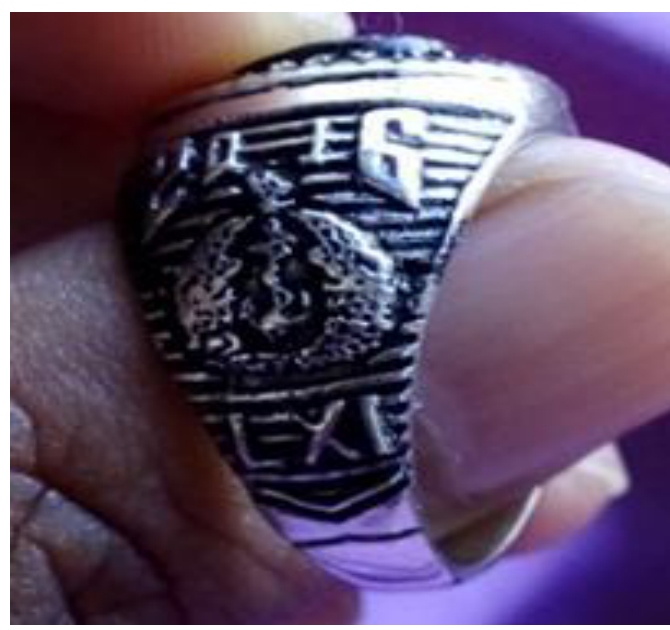

Figure 2. Sample of complex and detailed relief ring.

A simple method that usually used in jewellery production is by using rapid prototyping machine or $3 \mathrm{D}$ printer.

It is shown in Figure. 3 that 3D printer can realized complex and detail relief, but if we see more detail, due to its process, the surface finished is restricted by the step or layer thickness. The thinner the layer, the better the surface finish but the longer process is needed, but however this thickness is limited.

Another alternative is by using CNC. Complexity of product that could be realized using the $\mathrm{CNC}$ are depend on the axis number of $\mathrm{CNC}$, supporting jig and also 
machining strategy that defined by operator. The advantage is that the surface finish if better than one that produced by 3D printer, but complex surface with undercut is natural restriction. Figure 4 shows machining result using $\mathrm{CNC}$ engraver.

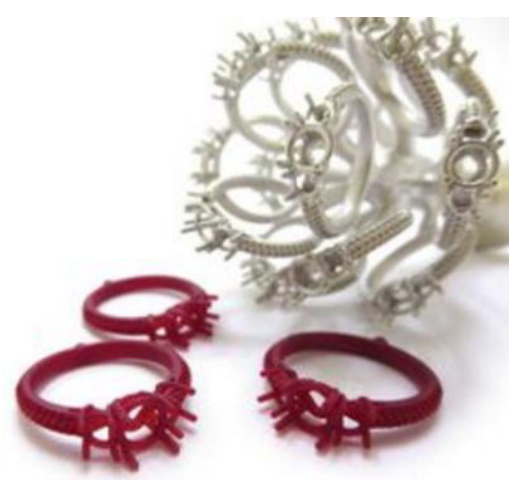

Figure 3. Jewellery master using rapid prototyping machine [2].
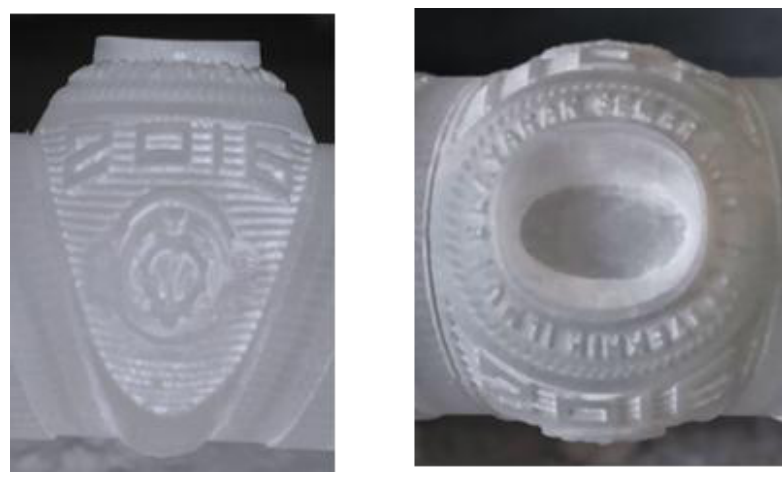

Figure 4. Jewellery master using CNC machine.

\section{Master Model}

Master model is one of the most important parts of the jewellery industry. A good model maker must know all the processes of jewellery manufacturing, including design, cast, polish, and stone setting [3].

All of those parameters should be taken into account, design, stone setting, and cast must be analysed in the design process either using engineering intuition or application software such as computer aided engineering (CAE). Since jewellery is made of precious metal, it is required to minimize polishing process to achieve its surface quality $[1,4]$.

From the illustration above, high quality surface is very important for a jewellery master model. It is not only reducing the polishing chip, but also improving the relief quality

\subsection{Types of Master Model Manufacturing}

Master model of jewellery can be made by using the process shown in Figure. 5. Depends on the relief complexity and production schedule, a wax (or resin) master can be prepared by manual, $\mathrm{CNC}$ or rapid prototyping machine.

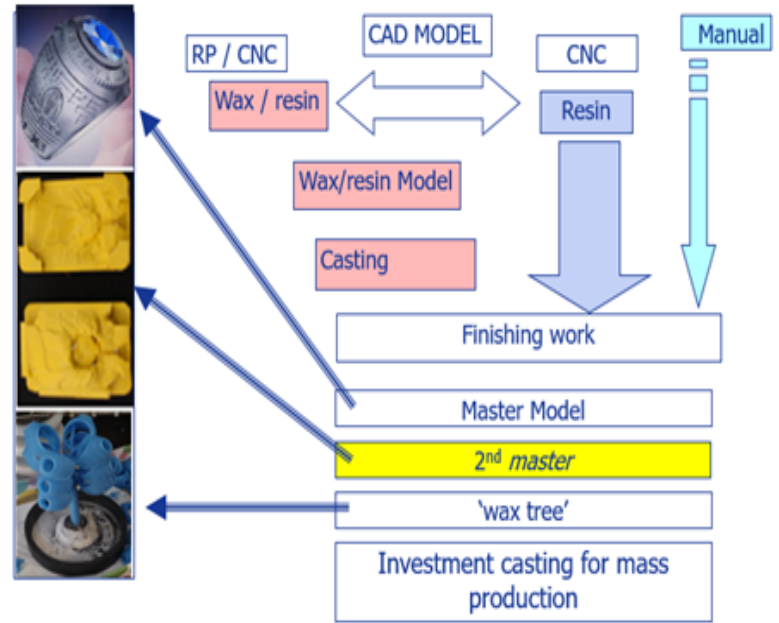

Figure 5. Jewellery master model making alternatives $[1,5]$.

In CAD/CAM based application, jewellery making is started using modelling wax or resin as material after its model is developed using digital modelling. Most are using rapid prototyping (RP) machine since it is very simple in implementation. The disadvantage is that the price is high and surface quality depends on its layer thickness. Thinner layer is better in surface quality, but thinner layer is longer time processing which will affect production time.

Another way is using the $\mathrm{CNC}$ machine. Compared with RP machine, this machine price is not expensive but it need high capability operator to handle. It can also produce product with better surface quality than those with RP machine.

In process which surface quality is not good enough, master jewellery preparation need further process to achieve its surface criteria as shown in Figure. 5. Things that should be noted here is that there are possibilities in dimensional changes that may affect relief geometry as well as stone setting due to thermal deformation and finishing process.

In the utilization of $\mathrm{CNC}$ machine. Jewellery master can be produced directly after machining, so that deformation and changes in relief and geometry can be minimized $[1,4,5,6]$.

\subsection{Jewellery Master Model Material}

In the utilization of $\mathrm{CNC}$ machine. Jewellery master can be produced from resin or mostly modelling wax.

\subsubsection{Polyester and Polyurethane Resins}

Polyester and polyurethane resins are the most commonly used casting material as shown in Figure.6. The polyester resin used in the moulding application is a viscous liquid requiring the addition of catalysts and accelerators to complete the curing process. Polyester resins are contact products which require no pressure to cure and can be cured from a fluid or solid state [7].

The advantage of polyester resin is that it is easy to use and is the lowest cost resin among resin products. However, there are a number of critical disadvantages in 
lack on mechanical properties and are less water resistant than polyurethane resins. The flash off of styrene during the curing process causes a fairly large degree of volumetric shrinkage, the full extent of which is often difficult to predict. Styrene emissions are also harmful and may necessitate the institution of specific, often expensive, environmental safety measures balance off ease of use, low cost, and positive physical characteristics. In many cases, polyurethane resin is produced in a liquid form and can be poured into moulds [7].

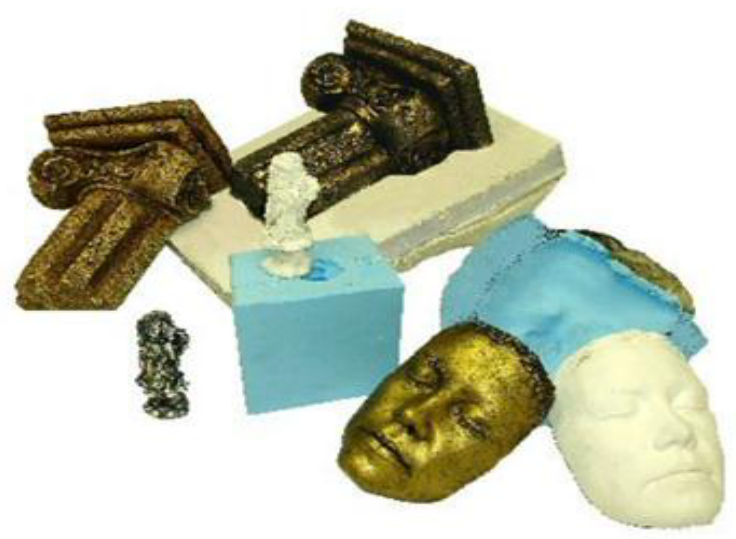

Figure 6. Sample of resin products [6].

There are many advantages to polyurethane resins. It can be formulated to create pliable rubber moulds and then be made into a hard plastic casting material or a water clear casting material [7].

Though polyurethane costs a bit more to manufacture, they have significantly better mechanical properties (stronger and more tear resistant), more importantly the emissions are extremely low when curing, and thus far safer to be around [7].
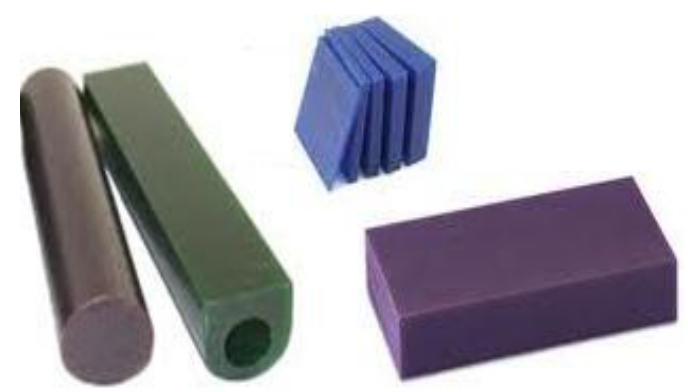

2.2.1

Jewellery Modelling Wax

Figure 7. Types of Jewellery modelling wax [8].

Most of commonly used material for Jewellery master is wax. Most CNC cannot produce product as it is designed especially undercut profiles, hence further process is needed to meet the design with real product. Using wax material, improvement can be easily done.

Disadvantages of jewellery wax is that there is electrostatic that is produced during machining process, so that the chip stuck in the product, and demagnetization is necessary to remove the stuck chips from product (see Figure.8). The other important is that wax is fragile, so that high clamping force will make it cracked or broken (see Figure.8).

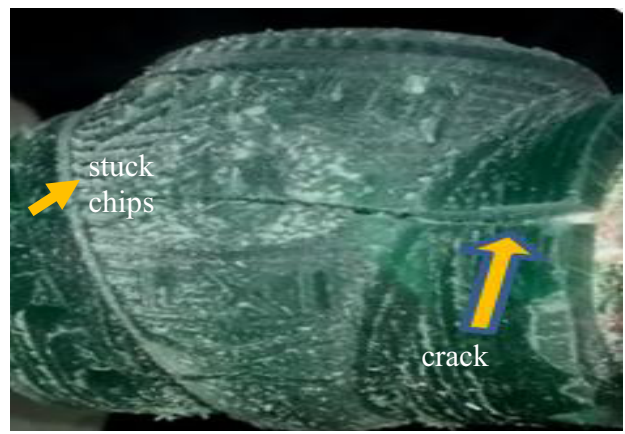

Figure 8. Sample of machining product using jewellery wax.

\subsubsection{Micromachining}

Micromachining is defined as fabrication of tiny devices: the techniques used in fabricating the miniaturized devices and moving parts into which microelectronic circuitry is integrated (Encarta, Encyclopedia).

Another definition as machining strategy where extremely small tool diameters are used. The tool characteristics are: diameter is in the range of 0.1 to 2 $\mathrm{mm}$, small cutting length, high accuracy, coated [8].

Machine requirement are high spindle accuracy, high rpm, thermal stability against spindle growth. The micromachining area is production of cavity, slot, pocket, holes or engraving in many type of material [9].

According to references, micromachining is usually done in semiconductor manufacturing, bio mechanics, jewelry, etc. Micromachining usually deals with laser cutting, layer manufacturing, chemical machining, etc.

In this paper, micromachining is used in term of machining jewelry master (master) using CNC milling machine with tiny single lip tool as shown in 0
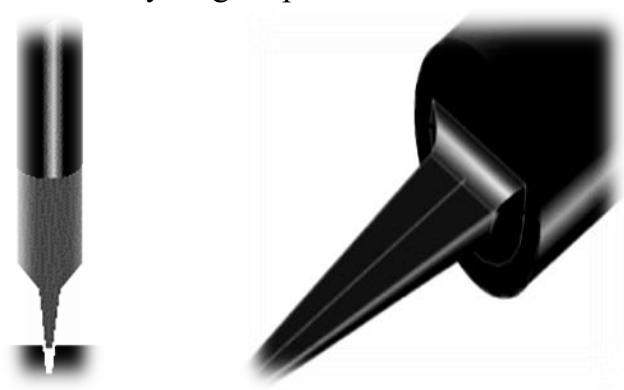

Figure 9. Conical tool [6].

\subsection{Research and Experiments}

JWX10 is a dry machine that not allow user to use liquid coolant or even lubrication for all slide ways. It has swing area of $66 \mathrm{~mm}$ in diameter, it means that work-piece and fixture volume is limited. Work-piece is attached and clamped in rotary axis in overhung position (see Figure.10). Due to that situation, deflection in at the edge will affect machining result. 


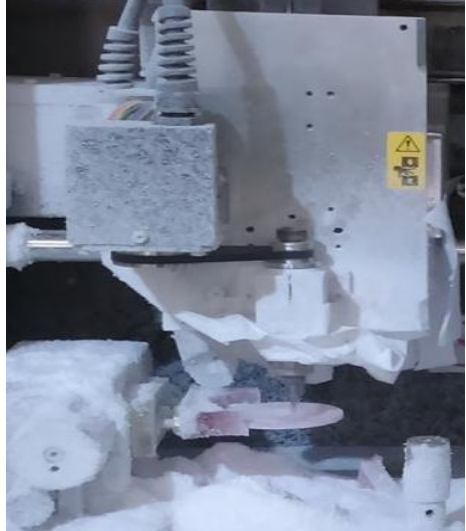

Figure 10. Machining setup.

Experiment is done by using Roland JWX10 CNC (Figure.10) and resin as work-piece (Figure.11). A detail model is illustrated in Figure.11. as a sample with $60 \mathrm{~mm}$ in diameter and total $3 \mathrm{~mm}$ thickness, double sided.

Machining is done under the condition shown in table 1., and use circular offset strategy as shown in Figure. 12. The simulation result is also seen in Figure.12.

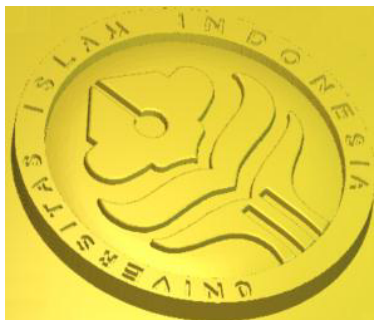

a.

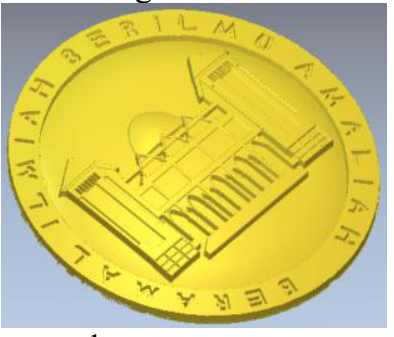

b.
Figure 11. Work-piece model, (a) Front-side, (b) Back-side.

Table 1. Machining condition.

\begin{tabular}{|l|r|r|}
\hline & Roughing & \multicolumn{1}{|c|}{ Finishing } \\
\hline Tool & End mill & Conical $\mathbf{4 0}^{\circ}$ \\
\hline Tip radius & $3 \mathrm{~mm}$ & 0.5 \\
\hline Feed & $7 \mathrm{~mm} / \mathrm{s}$ & $9 \mathrm{~mm} / \mathrm{s}$ \\
\hline Spindle & $15000 \mathrm{rpm}$ & $19000 \mathrm{rpm}$ \\
\hline Allowance & $0,35 \mathrm{~mm}$ & $0 \mathrm{~mm}$ \\
\hline Time & $20 \mathrm{~min}$ & $150 \mathrm{~min}$ \\
\hline
\end{tabular}
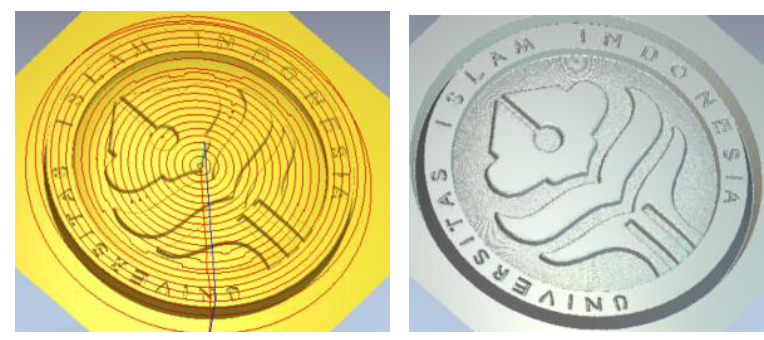

Figure 12. Machining strategy and simulation result.

That machining condition resulting surface as it is seen in Figure.13. It is shown that chips are collected and the adjacent area at the contact between tool and workpiece cannot moved away. That condition resulting temperature raised approaching resin's melting point $\left(250^{\circ} \mathrm{C}\right)$ especially between tool and work-piece contact.

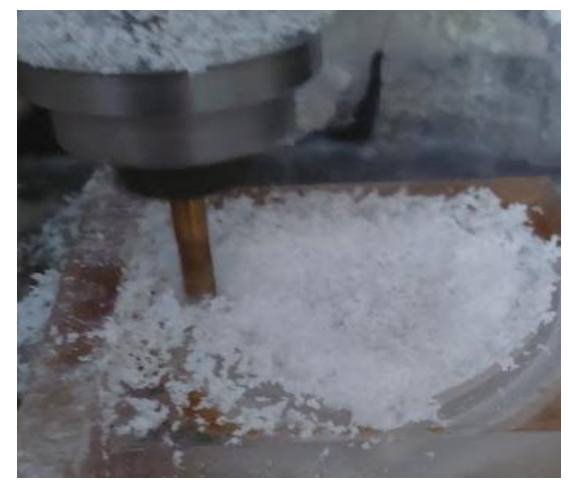

Figure 13. Machining situation, resin is collected, melt and stuck.
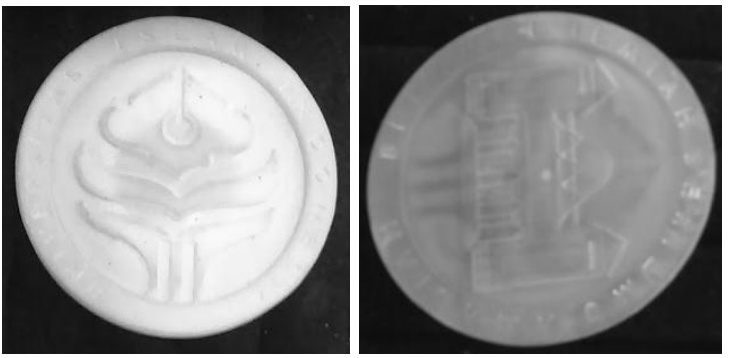

Figure 14. Machining result, resin chips is melt and stuck.

It is shown in Figure.14 that many part of machining result are in more white colour, showing that there are locations at which resin chip are melt and stuck on the surface and cannot be cleaned using tumbling or polishing process. Such abrasion process will affect surface finish quality or relief.

Resin material is a result of chemical reaction between resin solution and hardener. From this situation, cutting thin allowance will result very small particle of chip (see Figure.15). The tiny chips will then float and move with the air movement [11].

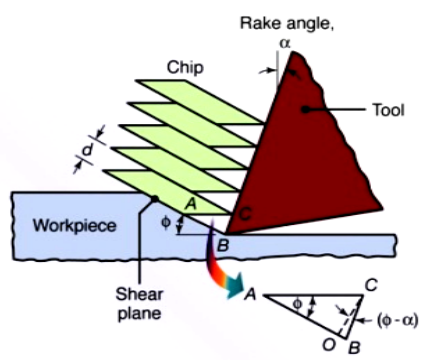

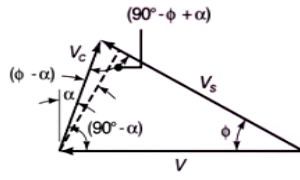

(b)
Figure 15. Shear phenomena in orthogonal cutting process [10].

With the very light weight the chip will move with the air from higher pressure (ambient pressure) into the spindle area. Spindle and tool rotate at very high speed, that make the air surrounding the area will have very low pressure, so that air will move into it.

During machining, most cutting energy will transferred into heat that will increase temperature in tool and work-piece area. When tiny chip is trapped in high temperature, it will be stuck in melted material and make poor surface finish quality. 
It is clear from Figure. 16 that the smaller step over the better surface finish, but the longer machining time. Bigger step over will also make the tool do not cut but hit the work-piece [5].

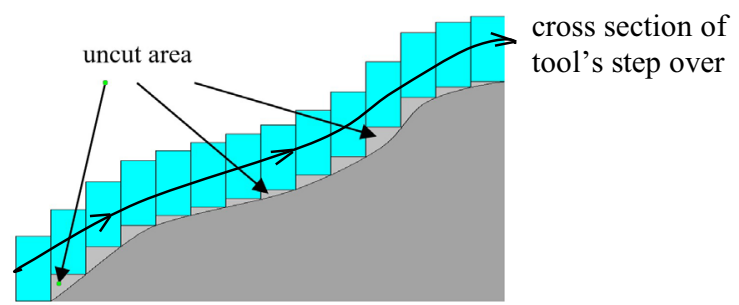

Figure 16. The effect of step over in tool movement to the surface quality $[1,5,12]$.

From the situation illustrated in Figure.16, Improvement is then made by increasing chip size to bigger volume without increasing step over (increasing depth of cut). Bigger volume is selected to absorb heat so that temperature will not raise high and also allow chip moved away by centrifugal forces of the rotating tool. With the bigger mass, chip is easier to move away from tool-work-piece contact area and does not follow the air flow (see Figure.17).

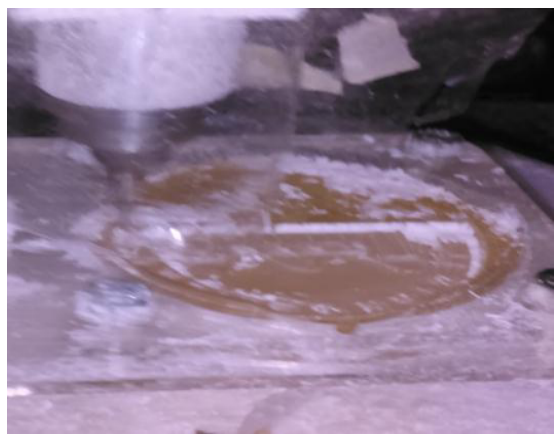

Figure 17. Bigger chip volume, chip is not stuck but moved away.

To make constant cutting forces, to avoid tool from broken, chip volume can be control by controlling the allowance in roughing step in machining. Using the allowance more than $1 \mathrm{~mm}$ resin will be cut with bigger chip sized form. This bigger sized chip will then throw centrifugally away from the tool and leave the surface area when it cut.

Since the chip are moved away, temperature is decreased, and nothing is stuck and better surface quality can be achieved (see Figure.18).
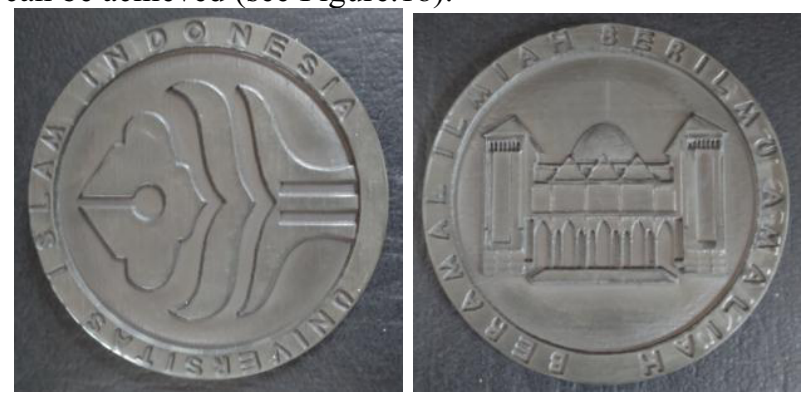

Figure 18. Machining result.

\section{Conclusions}

From the experiment, it is found that resin material that is suitable for jewellery model material has unique characteristic when it is machined, they are:

1. $200^{\circ} \mathrm{C}$ melting point make it critical to be machined since machining process will produce much.

2. Tiny sized chip from resin will float and flow with the air and may trapped into high temperature area and trapped and affect surface quality of machined resin.

3. Increasing depth of cut will increase chip volume and improve machine surface quality.

4. Increasing depth of cut will reduce machining step and improve total machining time significantly.

\section{Future Works}

After machining process, master model will be used to make rubber-mould. To do that, master will be placed in a silicon and vulcanized at about $170^{\circ} \mathrm{C}$. Simple model found no serious problem, but complex and thin model will. It is necessary to make another researches to find:

1. better material than resin

2. better type of silicon rubber

\section{References}

1. P. Puspaputra. Development of Machining Methode of Bitmap-based complex Surface. DT.JTM-ITB. (2012).

2. Pinterest. https://www.pinterest.com/laleipsig/3dprinting-2d-lasercutting/ (2016)

3. Goulds Jewellery, (http://www.gouldsjewellery.com /services/master-model-maker). (2016).

4. P. Puspaputra Micro-machining Problems in Undetermined Complex Surface (Case Study: Machining of Jewelry's Master Model), APIEMS C (2010).

5. P. Puspaputra. The Application of CAD/CAM Technology for Small Industries in Developing Creative Cultural Design of Art and Jewelry. APIEMS C. (2008).

6. P. Puspaputra. Single-Lip Tool Analysis for Jewellery Product Machining. RAPI-UMS.(2009).

7. Art Mould, https://www.artmolds.com/polyurethane. (2016).

8. Freeman Manufacturing, http://www.freemanwax.com/products.html. (2016)

9. Seco Tool, Jabro Catalog. (2006).

10. S.Kalpakjian, \& S.R.Schmid. Manufacturing, Engineering \& Technology (5th edition). P.E.Inc. NJ. (2006).

11. P. Puspaputra. A Study of Resin as Master Jewelry Material, a New Alternative Material to Perform Higher Complexity and Surface Quality of Jewelry Master using CNC. APIEMS C. (2016).

12. P. Puspaputra. Introduction to Bitmap-based $3 D$ Model and Its Machining Problems. Case Study: Brooch Machining. (IJENS - IJET), Volume: 12,(2012). 